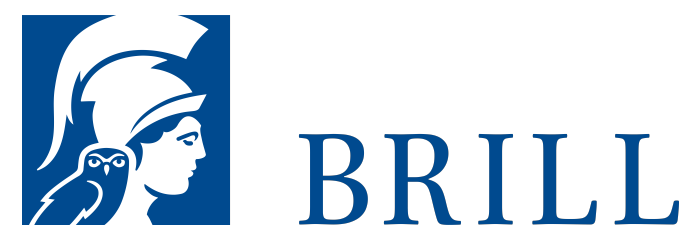

\title{
Electronic Chants: Groove from land to land
}

HipHop-Kultur aus der Bronx, Deutschland und Bosnien

Authors: Andrej Murasov and Andrej Murašov

HipHop-Kultur ist global: In jeder Sprache wird gerappt, gesampelt wird alles, von Soul Funk Breaks über Klassik bis hin zum folkloristischen Bläsersatz und auf Youtube tanzen B-Boys aus der ganzen Welt vor Wänden voller Graffiti.

Ausgehend von den frühen HipHop-Performances im New York der Siebziger untersucht der Autor die Entstehung der kulturspezifischen Körpertechniken im Kontext der elektronischen Medien und zeigt, wie Unterwanderungen technischer Konventionen die spätere Wanderung dieser Kulturpraxis und ihre lokale Reproduktion initiieren. Aus der Selbstinszenierung einer lokalen Gegenkultur wird im globalen Kontext eine Kultur der Selbstinszenierung, deren Widerstand sich nicht gegen ein kulturell Anderes, sondern gegen eine andere Kultur des Medialen richtet. Die Arbeit erklärt die medialen Dynamiken der Anfänge der HipHop Kultur anhand ihrer selbstreferentiellen Erzählstrategien in Rapmusik, Djing, Breakdance und Graffiti.

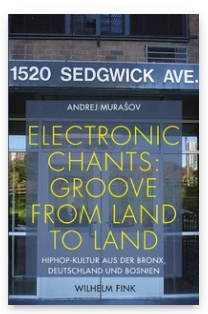

Pages: 287 Seiten, $14 \mathrm{~s} / \mathrm{w}$

Abb.

Language:

German

Subjects:

General, Musicology

Publisher: Brill |

Fink

E-Book (PDF)

Released online:

24 Nov 2017

ISBN: 978-3-

8467-6173-1

List price

Paperback

Publication date:

10 Nov 2017

ISBN: 978-3-

7705-6173-5

List price 
Andrej Murašov wurde 1983 in Starnberg bei München geboren. Er studierte Allgemeine \& Vergleichende Literaturwissenschaft, Amerikanistik und Südslawisitik an der Universität Bielefeld und der Ludwig-Maximilians-Universität München. 2015 promovierte er im Rahmen des Graduiertenkollegs „Funktionen des Literarischen in Prozessen der Globalisierung" an der LMU. Er arbeitet als freier Autor, Musiker und Sprachdozent in München.

For more information see brill.com

Order information: Order online at brill.com +44330 3330049 | customerservices@brill.com Submission information: brill.com/authors

Titles published by Brill | Fink, Brill | mentis or Brill | Schöningh: +49(o)71 5413279216 | brill@brocom.de 